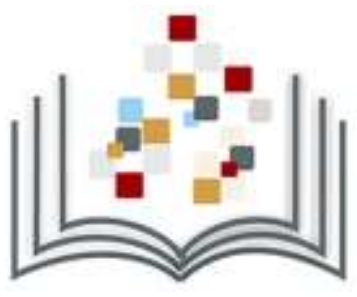

\title{
HUREVISTA: A EXPERIÊNCIA NOS ÚLTIMOS 10 ANOS E PERSPECTIVAS DE FUTURO
}

Maria Vitoria Hoffmann ${ }^{1 *}$, Thiago Gonçalves Schroder e Souza ${ }^{1}$, Hélady Sanders Pinheiro ${ }^{1}$, Rachel Delgado da Silva1 ${ }^{1}$, Florence Mara Rosa ${ }^{1}$, Angela Maria Gollner ${ }^{1}$

1 Universidade Federal de Juiz de Fora - Hospital Universitário - Juiz de Fora (MG) Brasil

*Autor correspondente: hoffmann-vick@hotmail.com

\section{Como citar:}

HOFFMANN, Maria V. et al. Hurevista: a experiência nos últimos 10 anos e perspectivas de futuro. In: WORKSHOP DE EDITORAÇÃO CIENTÍFICA, 9., 2016, São Paulo. Anais... São

Paulo: Associação Brasileira de Editores Científicos, 2016. p.44-48 DOI: http://dx.doi.org/10.21452/wec.IXwec.2016.0009

\section{RESUMO}

Criada em 1974, a HURevista, ISSN 0103-3123, é uma revista publicada trimestralmente pelo Hospital Universitário da Universidade Federal de Juiz de Fora (HU-UFJF). Está indexada nas bases de dados Lilacs (Index Medicus Latino Americano) e Índice de Revistas Latino-Americanas em Ciências e Rede de Apoio a Educação Médica (RAEM-ABEM), Sistema Regional de Información en Línea para Revistas Científicas de América Latina, el Caribe, España y Portugal (Latindex), Lilacs-Express. A revista objetiva a divulgação do conhecimento científico na área das Ciências da Saúde, na forma impressa e na forma online desde 2006. A revista utiliza acesso livre, através do Sistema de Editoração de Revistas (SEER), seguindo seus princípios de tornar gratuito o acesso aos resultados de pesquisa com intercâmbio global de conhecimento. Com acesso livre pretende-se aumentar o acesso e visibilidade. A HURevista utiliza o sistema Lots of Copies Keep Stuff Safe (LOCKSS) para distribuição dos volumes entre bibliotecas participantes, o que permite a criação de arquivos permanentes da revista para preservação e restauração. A HURevista aceita a submissão de artigos originais, comunicações breves, artigos de revisão, relatos de caso, em português e inglês. Nesse artigo, apresentamos a trajetória da HURevista a partir de sua inserção no SEER, as modificações implantadas, as estratégias utilizadas para atingir as metas de modernização e o retorno a periodização, bem como a redução da endogenia e aumento do número de manuscritos submetidos. Restam ainda muitos desafios que estão na dependência direta de fluxo permanente de recursos, um corpo editorial motivado e ágil e a ampliação do quadro de revisores.

\section{INTRODUÇÃO}

A HURevista, criada em 1974, como veículo de divulgação do Centro de Estudos Prof. Renato Loures, do Hospital Universitário da Universidade Federal de Juiz de Fora (HU-UFJF), com o nome inicial de HE Revista, passa, em 1984, a chamar-se HURevista - Revista de Medicina do Hospital Universitário. Posteriormente, deixou o Centro de Estudos e ampliou seus horizontes, tornando-se meio de divulgação científica do HUUFJF e das Unidades Acadêmicas que compõem a grande área da saúde da UFJF. 
Indexada nas bases de dados Lilacs, Index Medicus Latino Americano, Índice de Revistas Latino-Americanas em Ciências e Rede de Apoio a Educação Médica (RAEM$A B E M)$, publica manuscritos nas categorias: editorial, artigos originais, artigos de revisão, relato de caso, cartas ao editor e comunicação breve.

A partir do $\mathrm{n}^{\circ} \mathrm{32}$, referente ao ano de 2006, a estrutura da HURevista é totalmente reformulada. Esta mudança veio acompanhada da utilização do Sistema Eletrônico de Editoração de Revistas (SEER) para submissão online. Uma nova estrutura organizacional é implantada, com dois conselhos, um Conselho Editorial, para o qual foram convidados pesquisadores e professores de instituições locais e das várias regiões geográficas do Brasil, com intuito de abandonar uma configuração endógena e ampliar as possibilidades de participar da divulgação da produção científica do país. Alguns colaboradores internacionais também foram convidados. $O$ segundo conselho constituiu-se em um Conselho de Editores Associados, cujos membros são indicados pelas Unidades Acadêmicas com funções administrativas definidas de colaborarem com - Editor na construção do quadro de revisores, distribuir entre os revisores os manuscritos após check-list inicial para revisão entre pares. Estes conselheiros são também responsáveis pela aprovação final dos artigos a serem publicados. A utilização do SEER permitiu a criação de um banco de revisores, divididos por áreas de conhecimento, o cadastro de autores e a implantação de normas de publicação, atendendo as recomendadas pela Associação Brasileira de Normas Técnicas (ABNT) e Scientific Electronic Library Online (SciELO). Os descritores passaram a ser utilizados de acordo com Descritores em Ciências da Saúde (DeCS), disponível na Biblioteca Virtual em Saúde (BVS).

A linha editorial abrange as Ciências da Saúde, a fim de atingir profissionais desta área em geral, aceitando artigos em português e inglês (a partir de 2008).

Os avanços implementados favoreceram maior visibilidade do periódico e revisão de seus indicadores com melhor pontuação junto ao Qualis da Coordenação de Aperfeiçoamento de Pessoal de Nível Superior (CAPES). Ambicionando a inserção da HURevista na base de dados SciELO e PubMed, a equipe gestora vem adequando os critérios de editoração (normalização, gestão editorial, publicação, circulação) e os critérios de visibilidade (indexação em bases de dados, disponibilização do texto completo na internet), adotados a partir da edição online, para que este objetivo seja alcançado em médio prazo. Dentro da normalização, a ficha catalográfica e o International Standard Serial Number (ISSN) foram mantidos.

O objetivo deste artigo é descrever a trajetória da HURevista, seus desafios e vitórias após o início da edição online (2006).

\section{METODOLOGIA}

Trata-se de um estudo descritivo, realizado a partir de dados do site e de acervo documental da HURevista. A coleta de dados abrangeu o período de dezembro de 2007 a setembro de 2016. Foi feito inicialmente um diagnóstico da situação da HURevista, seus problemas, desafios e potencialidades.

\section{RESULTADOS E DISCUSSÃO}

A reestruturação da HURevista tornou-se necessária porque a mesma estava fora de periodização, o corpo editorial era muito grande, desmotivado e pouco produtivo. As avaliações dos manuscritos eram demoradas e quando enviadas aos autores, estes não apresentavam interesse nos mesmos, ou mesmo já haviam publicado o material em outros periódicos. A inserção dos artigos em base de dados também se encontrava desatualizada.

Diante deste cenário, em setembro de 2007, foi montada uma nova equipe editorial e instituída uma série de medidas para resgatar a periodicidade da revista e restaurar a credibilidade do periódico entre pesquisadores e leitores. 
Para dinamizar o processo de submissão, avaliação por pares e edição dos artigos foi instituído o formato online, com a utilização do SEER e a HURevista passou a contar com endereço eletrônico próprio.

O formato impresso foi mantido, com intuito de apresentar uma nova imagem que refletisse as mudanças instituídas; o periódico passou por ampla reformulação de diagramação, apresentando novos layouts para os artigos, a capa e o expediente da revista. Além disso, as normas bibliográficas foram reestruturadas com importante auxílio de renomada revisora com formação em biblioteconomia.

A estrutura organizacional da revista conta com um Editor e o Conselho Editorial revisado, que está constituído por 28 membros, com representatividade das áreas do conhecimento e já contamos com representantes de outras regiões do país (Figura 1). O aumento progressivo do número de componentes objetivou representar as áreas com maior contribuição no número de artigos submetidos e publicados (figura 2).

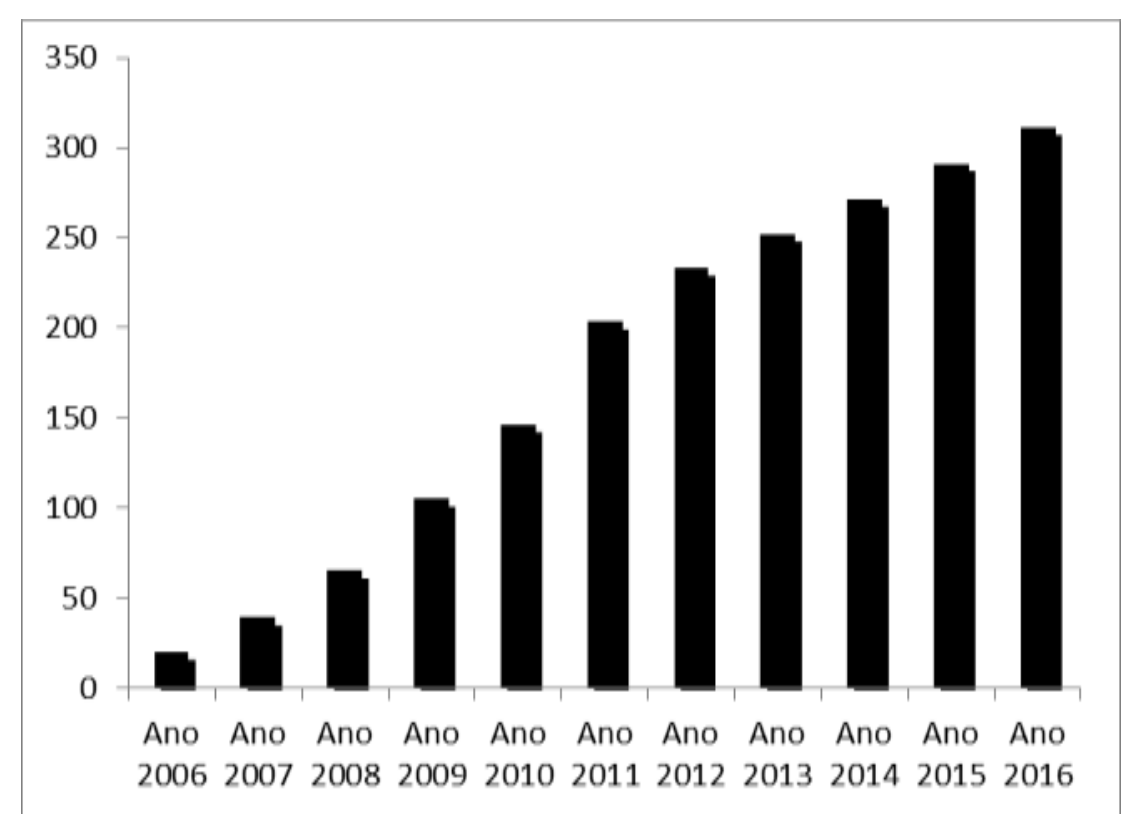

Figura : .Número cumulativo de artigos publicados na HURevista, no período de 2006-2016.

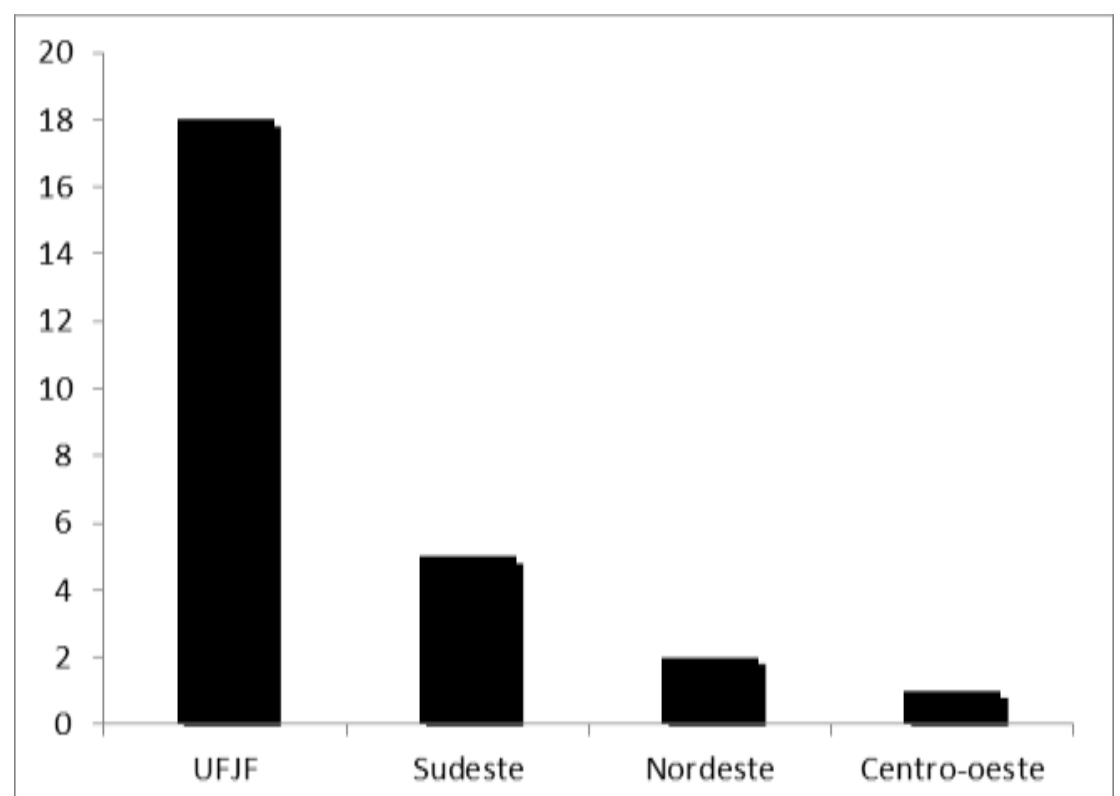

Figura 2: Número de Editores por região da HURevista, no período de 2006-2016.

A nova gestão, a dedicada equipe editorial e a colaboração de parceiros possibilitou a HURevista retomar sua periodicidade e apresentar crescente credibilidade no meio acadêmico, haja vista o aumento no número de artigos submetidos e de artigos 
originais publicados. A alavancada em número de artigos foi uma das metas estabelecidas e que já vem mostrando resultados positivos (figuras 2 e 3). Em relação ao perfil dos artigos publicados na HURevista, estes mostram que estão alinhados com o perfil da revista, que é a publicação da produção acadêmica das grandes áreas da saúde e afins (figura. 4). A maioria das publicações foi de artigos originais $72,2 \%$, dentre estes, talvez fruto da maior visibilidade, publicamos artigos de instituições de outros países.

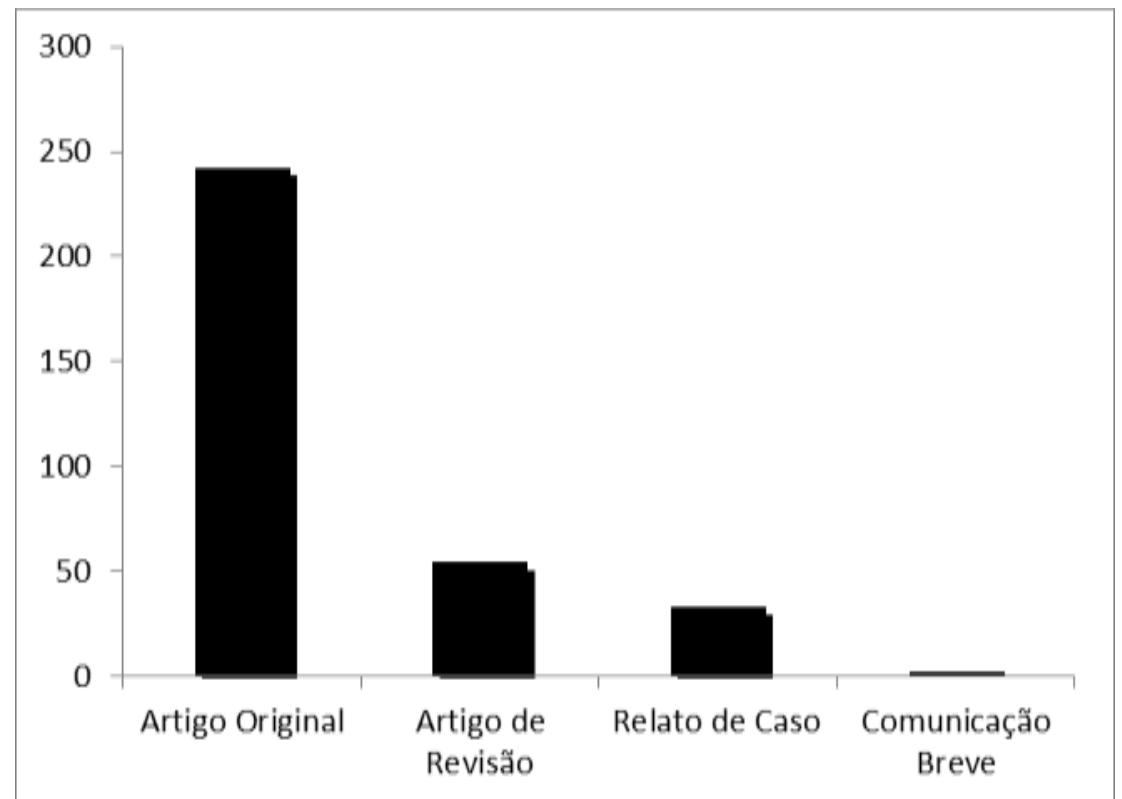

Figura 3: Número de artigos por tipo publicados na HURevista, no período de 2006-2016.

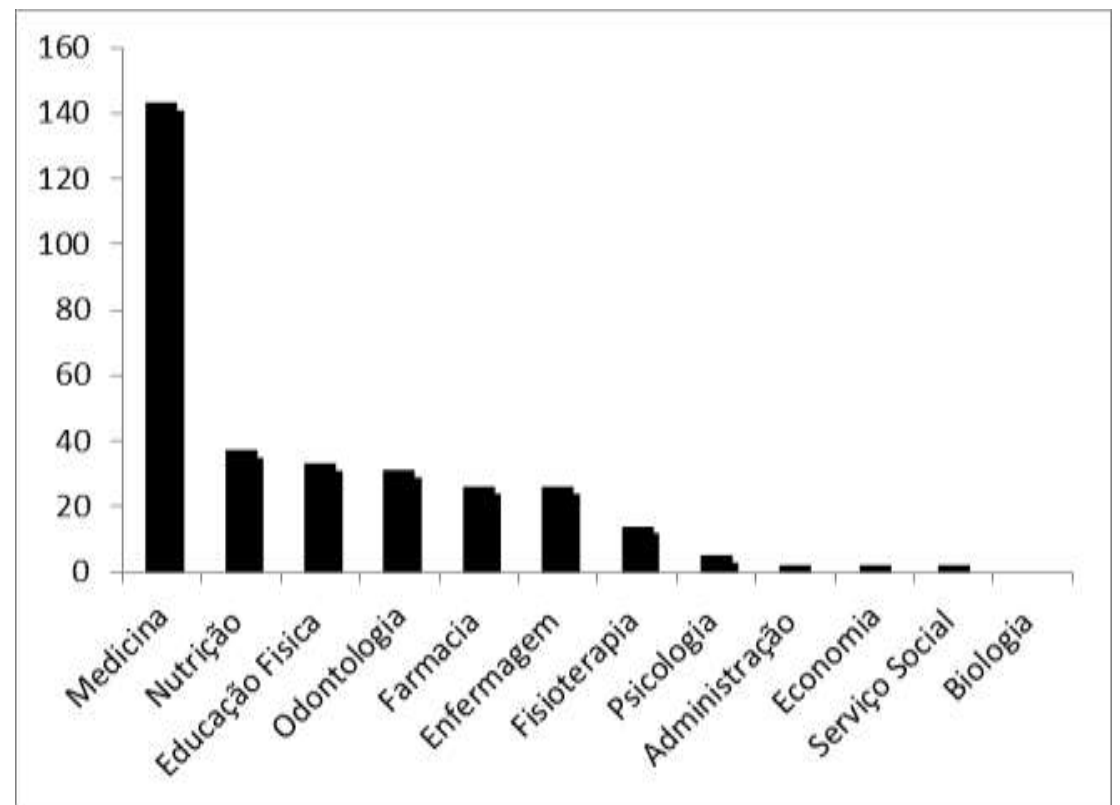

Figura 4: Áreas de artigos publicados na HURevista, no período de 2006-2016.

As indexações em novas bases e as atualizações dos dados nas bases já indexadas passaram a contribuir para o aumento da visibilidade.

Dos artigos originais, $30 \%$ são pesquisas qualitativas, $70 \%$ são quantitativas exploratório-descritivas e os de revisão têm sido de estudos do tipo bibliométrico. Os artigos rejeitados ainda representam um número pequeno em relação aos submetidos, e mesmo assim se devem às dificuldades de preenchimento de metadados, à falta de rigor teórico e de metodologia científica e à ausência de retorno dos autores após o encaminhamento dos pareceres para adequações. 
Sair da endogenia é uma meta e vemos como desafio a ampliação de publicações de artigos de outras instituições e países.

A redução do tempo transcorrido entre a submissão e a publicação dos artigos, embora venha apresentando redução significativa, ainda é uma das metas a serem trabalhadas pela equipe editorial da HURevista

O periódico passou também a ser indexado pelo Latindex e a integrar o Lilacs Express, consolidando-se na versão online. A HURevista recebeu recursos da Fundação de Amparo à Pesquisa do Estado de Minas Gerais (FAPEMIG) nos editais de 2009 e 2011, podendo assim finalizar as reformas editoriais em curso, além de manter a tiragem impressa.

A HURevista, tendo em vista que é uma revista jovem, ainda tem como desafios buscar e manter a regularidade; a pontualidade na editoração; a periodicidade de publicações; reduzir a endogenia; o tempo médio entre submissão e publicação; a possibilidade de ascensão dentro do percentual Qualis das revistas brasileiras. Podese considerar que, ao longo do caminho, a visibilidade internacional da revista melhorou. Neste momento, há proposta de se trabalhar para publicar o artigo em sua totalidade em inglês proporcionando, com isso, sua internacionalização. O financiamento para manutenção e implantação de um setor de tradução e obtenção do Digital Object Identifier (DOI), além de um corpo editorial motivado e ativo se fazem necessários. A qualificação da equipe editorial e sua valorização institucional são fundamentais para o alcance das metas descritas.

\section{CONCLUSÃO}

A HURevista, no seu formato online, avançou ampliando o número de artigos publicados, com um salto quantitativo e qualitativo, principalmente priorizando a publicação de artigos originais. Passou a contar com revisão por pares, com uma equipe qualificada, foi indexada em novas bases de dados, retomou sua periodicidade e credibilidade no meio acadêmico. Para avançar ainda mais, necessita de fluxo contínuo de financiamento, de fortalecer vínculos e construir novas e múltiplas parcerias.

PALAVRAS-CHAVE: Editoração. Publicações periódicas como assunto. Autoria e coautoria na publicação científica. 